\title{
Algunas reflexiones sobre: pluralismo, tolerancia y verdad
}

\section{Breve consideración sobre la problemática}

En las sociedades contemporáneas es muy común escuchar hablar sobre pluralismo y tolerancia. Se oyen voces que proclaman la benignidad del pluralismo -razas, culturas, ideas, etc.-, por considerarlo un factor que enriquece la vida de la comunidad. Otras tantas voces exaltan el fenómeno de la tolerancia como concepto clave en la lucha contra los fundamentalismos y piedra angular para la definitiva puesta en escena de formas marginales de comprender e interpretar el mundo, lo social, la vida humana, etc. Autores contemporáneos de diferentes corrientes de pensamiento hacen su opción por la tolerancia. Adela Cortina, por ejemplo, en su libro Ética de la Empresa, ${ }^{1}$ nota que las sociedades occidentales que han llegado a instituir formas de gobierno democráticas y donde han proliferado multiplicidad de maneras de interpretar el mismo fenómeno, sean estos religiosos, culturales, ideológicos, etc., demandan la existencia de sujetos abiertos al diálogo y a la búsqueda de soluciones colectivas dentro de un clima de tolerancia y respeto mutuo. También Richard Rorty, ${ }^{2}$ aunque desde una vereda diferente, alza su voz en defensa de la tolerancia como mecanismo de lucha contra los fundamentalismos. Para este autor las sociedades adolecen de una tendencia exclusivista respecto a su sentido de identidad y a la imagen que sus miembros tienen de sí mismos, partiendo de esta base las modernas sociedades occidentales pretenden arribar a la aceptación de las diferencias -tolerancia- mediante un acuerdo respecto a la verdad basada en la racionalidad de occidente, lo cual para Rorty, continúa siendo una actitud unilateral y por ende de intolerancia y fundamentalismo que niega las diferencias y no acepta que la verdad es en realidad la justificación de un sistema de creencias amparado en la tradición y no en aspectos de orden universal.

En muchas de las bocas que pronuncian las palabras pluralismo y tolerancia, resuenan éstas aún mezcladas con ecos de fundamentalismo y lo que debiera ser sinónimo de aceptación de la diversidad, se metamorfosea en una nueva forma de radicalismo, donde la concepción de la verdad se inserta como piedra angular del debate. De este modo, el

\footnotetext{
${ }^{1}$ Cf. CORTINA, Adela. Ética de la empresa. Claves para una nueva cultura empresarial. Madrid, Trotta. 2000. pp. 35-42.

${ }^{2}$ Cf. RORTY, Richard. El pragmatismo, una versión. Antiautoritarismo en epistemología y ética. Trad. Joan Vergés Gifra. Barcelona, Ariel. 2000. Pp. 79-82.
} 
significado de los conceptos pluralismo y tolerancia y la relación que mantienen con la noción de verdad que manejan los interlocutores de las actuales sociedades que se dicen a sí mismas pluralistas y tolerantes, son los principios que guían esta reflexión, cuyo propósito es el de tratar de desentrañar someramente el significado filosófico e histórico de estos conceptos, las relaciones que se establecen entre ellos y su vínculo con la idea de verdad.

\section{Pluralismo, tolerancia y verdad}

Si se tratan de establecer los límites del concepto pluralismo, se puede notar rápidamente que la pluralidad es un hecho de la existencia. La existencia humana se da siempre dentro de un contexto, el mismo se halla gobernado por creencias que guían todas las actitudes que el hombre pueda tener respecto a las situaciones que le acontecen. Estas creencias tienen que ver con pautas culturales, ideas vigentes, religión dominante, costumbres aceptadas, normas y valores morales compartidos, que dan forma a todo el sistema de representaciones del individuo que pertenece a dicho contexto.

La existencia del pluralismo no es un fenómeno nuevo, puede decirse que nació con la aparición del hombre mismo. Cada ser humano es diferente, si bien mucho de esto surge de cuestiones genéticas y vivencias psicológicas, también se da a causa de los diferentes contextos en los que cada uno se desarrolla -inclusive dentro de un mismo contexto las experiencias que se tienen pueden ser vividas por cada individuo de modo diferente-. Si se consulta cualquier tipo de obra literaria o de Historia de la Filosofía puede verse como muchos pensadores de la antigüedad habían notado esta divergencia o disparidad, no solo respecto a la conformación del individuo sino a las costumbres e ideales presentes dentro del aspecto cultural de los grupos humanos. Así, el polémico Protágoras ${ }^{3}$, advirtió que los mismos conceptos de impío y honorable, dependían de la interpretación que el propio hombre hiciera de ellos. Aún mucho antes que los filósofos, los poetas mostraron con sus cantos las diferencias socioculturales y cosmogónicas. En la Illiada, ${ }^{4}$ por ejemplo, Homero ofreció con sus relatos un panorama de la disparidad entre individuos, pueblos, culturas y creencias religiosas. Del mismo modo que Hesíodo reveló también una diferencia similar en su obra Los trabajos y los días. En fin, el tema de la pluralidad puede rastrearse a lo largo de toda la

\footnotetext{
${ }^{3}$ Cf. CARPIO, Adolfo. Principios de Filosofía. Una introducción a su problemática. Bs. As., Glauco. 1998. Pp. $59 / 60$

${ }^{4}$ Cf. HOMERO. Illíada, Canto I
} 
historia, simplemente porque lo plural es lo diverso y lo diverso es lo que nos define como humanos.

Lo que complica la cuestión no es la pluralidad, sino la idea de que esas diferencias estructurales deben ser toleradas y allí es donde surge el inconveniente y aparecen los fundamentalismos. El mismo Protágoras fue acusado por sus contemporáneos de relativizar lo social, de insertar el caos dentro de la jerarquía de bienes y valores existentes, por eso fue llamado sofista, en el sentido peyorativo del término, no obstante, su idea de hombre como medida de todas las cosas más que alterar el orden, ofreció una nueva perspectiva de análisis menos dogmática y más abierta a lo heterogéneo. Puede decirse que la antigüedad occidental fue más rica en aceptación de la diversidad que la Edad Media. Los romanos, por ejemplo, llegaron a implementar el culto a los dioses desconocidos, donde queda de manifiesto el reconocimiento de la diversidad de creencias y el pluralismo religiosos. Incluso, no sólo permitieron a los pueblos conquistados seguir practicando sus ritos, cosa que Maquiavelo ${ }^{5}$ admiraba de Alejandro Magno, sino que los incluyeron dentro de su sistema imperial.

Este panorama de cierta tolerancia religiosa es rechazado dogmáticamente durante el medioevo por la Iglesia Católica, quién puso todo su arsenal al servicio del combate de las diferencias y de lo múltiple, en todos los ámbitos. Pluralidad y tolerancia deberán aguardar al renacimiento y a la época moderna para resurgir nuevamente con figuras como Montaigne, Locke, Montesquieu, etc.

Pluralidad y tolerancia no son conceptos que de hecho puedan ser asimilados entre sí, ya que la pluralidad existe independientemente de que esté acompañada de tolerancia. Pluralidad implica lo otro, lo diferente de mí, que demanda una actitud de apertura hacia el exterior que se manifiesta en el mismo contacto entre los individuos, donde me muestro como soy desde el centro mismo de mi conformación subjetiva. La pluralidad es el uno duplicado, no el uno inmóvil de Parménides, ${ }^{6}$ sino el uno individuo, materia, que se forma y transforma a través de su existencia en el mundo y que al enfrentarse con otros despliega su propia singularidad, su educación, su contexto, su pensamiento. Por esta razón, puede decirse que plural es un término reversible, porque el otro es diferente para mí, pero yo también me convierto en la diferencia para el otro. Esta vinculación del individuo con lo material permite sólo una percepción parcial del mundo, la asociada al ámbito de interacción física del mismo. No obstante, esta percepción se reproduce casi intacta entre los miembros de una misma

\footnotetext{
${ }^{5}$ Cf. MAQUiAVElO, Nicolás. El Príncipe. Trad. Antonio D. Tursi. Bs. As., Biblos. 2003. Pp. 34-36.

${ }^{6}$ Cf. CARPIO, Adolfo. Pp. 23-27.
} 
comunidad por los lazos de proximidad espacial y contextual que existen entre ellos, dando lugar a un tipo específico de conciencia de la realidad, tal como lo sostuvo Marx.

"La conciencia es, ante todo, naturalmente, conciencia del mundo inmediato y sensible que nos rodea y conciencia de los nexos limitados con otras personas y cosas, fuera del individuo conciente de sí mismo."

En este sentido la pluralidad individual producto de la propia percepción y vivencia del mundo, encuentra un núcleo unificador en la misma proximidad espacial que conduce a los pueblos a compartir una determinada visión de las cosas. Esta perspectiva parcial desde la cual se observa y entiende al mundo es la responsable de la diversidad de creencias que imperan entre las culturas.

Tolerancia, en cambio, es un término al que se lo utiliza con dos significaciones disímiles. La primera de ellas, tiene que ver con el uso cotidiano y se la usa como sinónimo de 'soportar'. Como la palabra 'soportar' implica la no aceptación de las diferencias, la idea de tolerar dentro de este contexto estará emparentada con palabras negativas como callar, resistir, sufrir, aguantar o llevar la cruz, disimular, entre otras. Así tolerar significará lo que no acepto aunque lo sobrelleve con disimulo al menos por un tiempo. Dentro de esta manera de entender el concepto tolerancia, juega un rol central la propia cosmovisión del mundo, la cual es vivida como la verdad desde una posición casi etnocentrista. La segunda manera de entender el término tolerancia hace referencia a la aceptación o como diría Ernesto Laclau "La tolerancia sólo comienza cuando desapruebo moralmente algo y, sin embargo, lo acepto". 8 Tolerar, dentro de este contexto, quiere decir reconocer las diferencias estructurales entre nosotros y aceptarlas, sin tener que fingir que compartamos esa manera de pensar, pues "si lo que tolero es lo que apruebo moralmente (o, al menos, aquello frente a lo cual soy moralmente neutral) no estoy tolerando nada (...)". 9

La relación entre los conceptos pluralismo y tolerancia, resulta bastante peculiar ya que pluralismo no incluye dentro de su extensión al término tolerancia, pues, como ya se dijo, hay diversidad sin que ésta sea aceptada. Es decir que, puede haber pluralismo sin que por ello necesariamente lleguemos a la idea de tolerancia. Por otro lado, si invertimos los términos, tolerancia no tiene la extensión necesaria para contener a pluralismo, solo a expresiones positivas como aceptar, o negativas como soportar, las que se encuentran

\footnotetext{
${ }^{7}$ MARX, Carlos y ENGELS, Federico. La ideología alemana. Trad. Wenceslao Roces. Bs. As., Pueblos UnidosCartago. 1985. P. 31.

${ }^{8}$ LACLAU, Ernesto y otros. Deconstrucción y pragmatismo. Trad. Marcos Mayer. Comp. Chantal Mouffe. Bs. As., Paidós. 2005. P. 105.

${ }^{9}$ Ibidem.
} 
asociadas de modo contingente con la materia sobre la que se aplica dicha actitud, y que dependen en gran medida de la comprensión que se tenga del concepto tolerancia. No obstante, tolerancia se encuentra necesariamente vinculada a pluralismo. En efecto, no puede haber tolerancia, sea positiva o negativa, sin que ésta esté acompañada de la existencia de cierto grado de multiplicidad. El pluralismo es el que brinda la oportunidad de la aceptación, es condición necesaria para la tolerancia, es el marco dentro del cual cobra sentido la idea misma de aceptación, pues sin la existencia de la diferencia no habría posibilidad para que ella se manifieste ya que todos comulgaríamos con las mismas ideas y como lo sostiene Laclau en la cita precedente, la tolerancia es la aceptación de la no aceptación y no la aceptación de lo aprobado.

\section{Obstáculos en el camino hacia la tolerancia}

Desde nuestro criterio detectamos tres errores frecuentes que dificultan la puesta en práctica de actitudes tolerantes dentro del marco de pluralidad supuestamente reconocido y avalado a nivel internacional como factor de enriquecimiento sociocultural. Ellos son: 1) pensar etnocentricamente; 2) creer que las diferencias pueden ser suprimidas y 3) estimar que la tolerancia es una actitud meramente individual.

1) la primera dificultad para lograr una actitud tolerante es pensar al pluralismo etnocentricamente, no ver al otro como un ser humano igual a mí salvo que con un pensamiento distinto, sino apreciarlo como diferente y por ende inferior. En este caso se cree que nuestra verdad es la verdad con mayúscula, mientras que la verdad de los otros es en realidad algo equivocado. Quienes se paran en esta vereda, tienden a considerar que su cultura ha avanzado de una manera más rápida, que han llegado a la captación de valores superiores antes que otros pueblos. En definitiva parten de la idea de que la verdad es algo que se halla, que se encuentra, que se descubre. Esta verdad estará, respecto al sujeto poseedor de la misma, en un plano exterior y dependerá de factores que escapan a su ingerencia. De este modo la verdad adquiere un estatuto de universalidad que niega la posibilidad de que sea alterada por otros factores sean éstos humanos, sociales, culturales, ideológicos, etc. Dentro del contexto que ofrece el mundo actual, la verdad con mayúscula es occidental y cristiana, por consiguiente todo lo que no se adapte al este modelo se considerará como lo otro, lo exótico o, en el mejor de los casos, lo propio de pueblos cuyo grado de evolución del espíritu se encuentra en una etapa muy rudimentaria, como opinaba Montesquieu. Pero la verdad no 
es algo que se encuentra, sino algo que se construye socialmente como sostiene Rorty. ${ }^{10} \mathrm{Sin}$ embargo, hay que destacar que Montesquieu no estaba tan equivocado, pues, mediante el enfoque que da a su análisis logra reconocer que los factores geoambientales ${ }^{11}$ ejercen una fuerte influencia sobre la conformación de la subjetividad de los pueblos, solo que equivoca su conclusión al dejarse guiar por su propia subjetividad, hecho que lo lleva a exaltar a la cultura occidental como superior frente a la no occidental, cuando sólo debería apreciarla como diferente. En efecto, el error de Montesquieu no radica en plantear que los pueblos evolucionan atendiendo también a factores geográficos y culturales, sino en construir una jerarquía que tiene a la cultura europea en su cúspide. Así, el auriga platónico de Montesquieu que llegará a la idea de bien será europeo y cristiano.

Para superar la dificultad que opone el pensamiento etnocéntrico a los efectos de lograr actitudes de tolerancia, debe tomarse conciencia primero de que la verdad es algo que se construye. Construir implica necesariamente la participación de varios actores, que son a la vez miembros de una comunidad, ésta a su vez, se encuentra inserta dentro de una historia y tiene un legado cultural -formas de hacer y entender- que la dirigen. Cada comunidad es diferente entre sí y elabora sus propias verdades sin que ninguna pueda imponer a la suya como la mejor. Hasta aquí puede objetarse que, de entender la verdad de esta manera, caeríamos en un relativismo superior incluso al de Protágoras, pero eso no es así. Si alguna enseñanza han dejado el pragmatismo y el utilitarismo, es que no hay verdades absolutas sino verdades a medias, las cuales pueden mezclarse entre sí para obtener algún tipo de pequeña verdad con la que todos podamos coincidir y que permita a las sociedades seguir funcionando de algún modo compatible con sus diferencias internas y externas.

2) el segundo error es creer que las diferencias pueden ser suprimidas, es una variante del anterior. Éste radica en una tendencia reduccionista que lleva a pensar que lo múltiple puede ser absorbido y transformado en uno, mediante el camino de la evolución del pensamiento y las ideas. Montesquieu ${ }^{12}$ sigue siendo un claro ejemplo de esta actitud. En su teoría del espíritu de los pueblos, pretende ver que los mismos evolucionan culturalmente hacia formas más perfectas al aceptar concepciones donde la idea de libertad se amplía. El

\footnotetext{
${ }^{10}$ Cf. RORTY, Richard. Contingencia, Ironía y Solidaridad. Trad. Alfredo Eduardo Sinnot. Barcelona, Paidós. 1996. Pp. 23-29.

${ }^{11}$ Factor al que hasta el mismo Marx otorgó importancia como fenómeno decisivo en el proceso de organización de las sociedades, las cuales, según este autor, se desarrollan hacia uno u otro lado en función de los recursos naturales con los que se encuentran.

${ }^{12}$ Cf. MONTESQUIEU. Del espiritu de las leyes. Trad. Mercedes Blázquez y Pedro Vega. Madrid, Tecnos, 4 ed. 1998. Pp. 10-11.
} 
autor define libertad como el respeto a las leyes. Estas leyes pueden ser naturales o positivas. Si son naturales rigen tres estadios básicos en el desarrollo del individuo, la conservación vital, momento en que el individuo se encuentra aislado del todo, aún no es sujeto sino simple entidad individual; la que manda la procreación como exigencia natural que lleva a la conservación de la especie, aunque también reúne o posibilita la reunión y el intercambio; y la última, que despierta en el hombre la necesidad de conformar la sociedad -aún no civil-, promovida por la búsqueda de conocimiento que se despierta en los individuos cuando se detectan desigualdades. Si son positivas, rigen la vida dentro de la sociedad civil y se aplican a todos los hombres sin distinciones.

Pero, tanto la idea de libertad, como la de ley, sostenidas por Montesquieu parten de modos occidentales de entenderlas, de allí que la ampliación que propone no sea más que una mera aceptación de la superioridad de la cultura occidental cristiana. En efecto, son los otros pueblos quienes deben reconocer la superioridad de estas concepciones y hacerlas suyas para evolucionar culturalmente y convertirse en pueblos 'civilizados'. Lo negativo de esta postura es que establece una jerarquía en la que necesariamente se introducen las categorías de bueno y malo, superior e inferior, occidental y no-occidental, que llevan a suponer que, si todos los pueblos llegaran al nivel más alto de evolución -representado en la cultura de occidente-, sea voluntaria o involuntariamente, podrían suprimirse las diferencias. De este modo, la diversidad no es vista como un hecho de la naturaleza sino producto de la falta de educación propia de los pueblos que viven en regímenes donde la libertad se halla restringida.

3) el último de los errores integra en sí mismo a los dos anteriores, quienes incurren en el estiman que la tolerancia es una actitud meramente individual, que se despierta en cierto tipo de personas con una predisposición especial del espíritu hacia la aceptación pasiva. Ahora bien, entender el fenómeno de la tolerancia como una tendencia individual intrínseca conlleva dos peligros, el primero, desvincularla de la comunidad y por ende negarle su estatuto de valor moral transmisible a las generaciones futuras y segundo, reducir la posibilidad de la práctica de la tolerancia a un sector de la humanidad, aquellos que se encuentran dentro de la categoría 'espíritus pasivos'. Por consiguiente estamos en condiciones de afirmar que, el error de esta concepción radica en el mismo presupuesto del que parte, pues confunde una práctica proveniente de la formación cultural con una forma de ser típica de ciertos individuos.

\section{Consideraciones finales}


El pluralismo es un hecho natural de la existencia, siempre estuvo presente en todas las sociedades y siempre estará, porque es una manifestación de la vida misma, no existen dos individuos iguales, ni siquiera dentro de una misma cultura. La tolerancia, en cambio, es una actitud que se sustenta en un valor transmisible culturalmente y como todo valor, requiere del ejercicio permanente de dicha actitud -habito- para que logre arraigarse de modo permanente en el individuo -costumbre-. Pluralismo -naturaleza- y tolerancia -costumbre-, no pueden dejar de entrar en interacción dado que ambas se dan en el plano de la vida humana, ámbito de la existencia conciente capaz de captarlas. La verdad se presenta dentro de este contexto, como la herramienta que permite al individuo clasificar la información proveniente del exterior -naturaleza- como válida o inválida. En base al criterio obtenido de este proceso elige el curso más conveniente para su acción -tolerancia/intolerancia-. La opción por una u otra vía de acción, queda, a su vez, justificada por la misma concepción acerca de la verdad que el individuo maneja y por la formación-información mediante la cual se lo moldeo en el proceso formativo de su vida. Es decir que, si el individuo cuenta con una idea de verdad dogmática y cerrada, apreciará las creencias de los demás como equivocadas y la actitud que asumirá frente a ellas será la de la intolerancia. Por el contrario, si acepta que la verdad es algo que se construye y que el mismo sujeto participa activamente en esta construcción, su actitud se tornará en aceptación de las diferencias.

Sólo si se acepta como veraz la premisa de la verdad como construcción humana y social, podrán cobrar sentido conceptos como pacto, aceptación y consenso, dado que la misma será entendida como un acuerdo contingente al que se llega mediante la aceptación abierta de las diferencias y el posterior consenso sobre algunos pequeños puntos que permitirán al individuo, una actuación tácitamente válida dentro de los límites restringidos de un entorno socio-cultural particular. Lo cual no quita que esta actuación no pueda ser coincidente y compartida por otros individuos provenientes de diferentes entornos, aunque esto ocurra sólo de modo accidental. Es en este aspecto donde nuestra reflexión comulga con el pensamiento de Rorty, pues no es posible construir una sociedad y tratar de alcanzar un mínimo de tolerancia universal, mientras se mantengan vigentes criterios universalistas y cerrados en torno a la verdad, que excluyen de su significación a concepciones periféricas de entender el mundo y sus manifestaciones.

A pesar de que Rorty sea por excelencia el filósofo de la contingencia, otros pensadores de diferentes ámbitos y corrientes también reconocen que tolerar implica apertura, pacto y consenso, sea en el ámbito de lo político o de lo cultural. Adela Cortina con su ética 
cívica muestra un claro ejemplo de la decadencia en la que cayeron, al menos en España, las concepciones universalistas de la verdad luego del derrumbe del Estado confesional que las sustentaba y mantenía. La ética cívica, como la dialógica de Apel, se basa en el dialogo entre los afectados, quienes nunca son todos sino solo una parte contingente, quienes intentan establecer un consenso que permita a lo social seguir funcionando mediante la aceptación de las diferencias sociales y culturales provenientes de la heterogeneidad de la población.

Lo mismo ocurre en el terreno de lo político, Chantal Mouffe al igual que Ernesto Laclau, reconocen que en los sistemas políticos donde imperan formas de gobierno democráticas el pluralismo de ideas es moneda corriente. Por lo tanto dentro de este contexto el consenso siempre será provisional. En efecto, si aceptamos la idea de que el pluralismo existe como fenómeno propio del ser humano y que la democracia es la única forma de gobierno donde éste puede manifestarse, no podemos adherir a una concepción universalista de la verdad, porque caeríamos necesariamente en el totalitarismo y la imposición, aunque el fin sea lograr un consenso permanente. La misma democracia al aceptar concepciones tan diversas dentro de sí gestiona el conflicto y vuelve provisorias a las soluciones. En sociedades donde la palabra tolerancia es entendida como sinónimo de soportar el consenso será aún más débil, pues siempre habrá descontento en un sector de la misma.

De este modo pluralismo -naturaleza-, tolerancia -costumbre- y verdad -justificación-, se entrelazan en la existencia humana como partes indisolubles de un todo, que determinan la conducta en base a concepciones prefijadas provenientes de la cultura y que pueden inclinar la balanza hacia dos formas de percibir a los otros, la aceptación o el rechazo. 